\title{
Baca Gazı Destekli Organik Rankine Çevrimi için Taguchi Analizi
}

\author{
Burak Türkan* \\ Bursa Uludağ Üniversitesi, Gemlik Asım Kocabıyık MYO, Makine Bölümü, Gemlik, 16600, Bursa/TÜRKIYE (ORCID No: 0000-0002-4019-7835) \\ burakt@uludag.edu.tr
}

(2nd International Conference on Applied Engineering and Natural Sciences ICAENS 2022, March 10-13, 2022)

(DOI: $10.31590 /$ ejosat.1082626)

\begin{abstract}
ATIF/REFERENCE: Turkan, B. (2022). Baca Gazı Destekli Organik Rankine Çevrimi için Taguchi Analizi. Avrupa Bilim ve Teknoloji Dergisi, (34), 381-386.
\end{abstract}

\section{$\ddot{O} \mathbf{z}$}

Atık 1Sı geri kazanımının önemli bir rol oynadığı gelecekteki enerji talebi ve çevre kirliliği sorunlarının hesaplanmasında verimlilik çoğu zaman birincil faktördür. Organik Rankine çevrimi (ORC), düşük ile orta dereceli atık 1sı kaynakları için teknik uyumluluk, fizibilite ve güvenilirlik nedeniyle araştırmacıların ve/veya üreticinin yaygın ilgisini çekmeye devam etmektedir. Bu makale, enerji ve ekserji kavramlarına dayalı olarak baca gazı destekli organik Rankine çevrimleri üzerine optimizasyon analizi sunmaktadır. Bu çalışmada, termal enerjiyi elektrik ve/veya mekanik enerjiye dönüştürmek için iki türbinli çevrim kullanılarak Taguchi metodu ile optimizasyon çalışması yapılmıştır. Optimizasyon çalışması için parametreler, türbin giriş basıncı $\mathrm{P}_{1}$, çevrim ara basıncı $\mathrm{P}_{2}$ ve türbinden ara basınçtaki isı eşanjörüne aktarılan akışkan oranı PC3 olarak seçilmiştir. Elde edilen sonuçlara göre ORC çevriminin birinci ve ikinci kanun verimleri üzerinde en etkili parametrenin türbin giriş basıncı (1. kanun için \% 70.23, 2. kanun için \% 72.38) olduğu tespit edilmiştir.

Anahtar Kelimeler: Organik rankine çevrimi, Taguchi, Optimizasyon, Ekserji.

\section{Taguchi Analysis for Flue Gas Assisted Organic Rankine Cycle}

\begin{abstract}
Efficiency is often the primary factor in calculating future energy demand and environmental pollution problems, where waste heat recovery plays an important role. The organic Rankine cycle (ORC) continues to attract widespread attention from researchers and/or manufacturers due to its technical compatibility, feasibility and reliability for low to moderate waste heat sources. This article presents optimization analysis on flue gas assisted organic Rankine cycles based on energy and exergy concepts. In this study, an optimization study was carried out with the Taguchi method using two turbine cycles to convert thermal energy into electrical and/or mechanical energy. The parameters for the optimization study were selected as turbine inlet pressure $\mathrm{P}_{1}$, cycle intermediate pressure $\mathrm{P}_{2}$ and fluid ratio PC3 transferred from the turbine to the heat exchanger at intermediate pressure. According to the results obtained, it has been determined that the most effective parameter on the first and second law efficiencies of the ORC cycle is the turbine inlet pressure (70.23\% for the 1 st law, $72.38 \%$ for the 2 nd law).
\end{abstract}

Keywords: Organic rankine cycle, Taguchi, Optimization, Exergy.

\footnotetext{
*Sorumlu Yazar: burakt@uludag.edu.tr
} 


\section{Giriş}

Günümüz dünyasında mühendislerin karşılaştığı zorluklardan biri, düşük başlangıç sermaye yatırımı ile uygun maliyetli ve aynı zamanda düşük işletme maliyetine sahip, çevre koruma konusundaki hükümet gereksinimlerini karşılayan bir sistem tasarlamaktır. Enerji talepleri artarken, doğal kaynaklarımız azalıyor ve her geçen gün kaynaklarımızı daha verimli kullanmak giderek daha önemli hale geliyor (Pulat vd., 2009).

Tarih boyunca enerji arzı her zaman insan yaşamının ihtiyaçlarından biri olmuştur. Günümüzde küresel talebi artarak devam eden enerji arzının birincil kaynaklarından biri elektriktir (Alirahmi vd., 2021). Yenilenebilir enerji, fosil ve yenilenemeyen kaynakları tüketmeden modern yaşamı hareket ettirmek için sonsuz bir enerji kaynağı vaat ediyor. Çevre kirliliği ve iklim değişikliği, fosil yakıt kullanmanın yüksek ekonomik maliyetleri göz önüne alındığında, araştırmacılar bunları yenilenebilir enerji ile değiştirmeyi düşünüyorlar (Soltani, 2020).

Organik Rankine çevrimi, düşük kaynama sıcaklıklarına sahip organik malzemeleri çalışma sıvısı olarak kullanarak atık 1sıyı güce dönüştürür ve basit yapısı, farklı çalışma koşullarına kolayca uygulanabilmesi, boyutu ve güç üretme kabiliyeti nedeniyle organik Rankine çevrimi, düşük dereceli atık 1S1 kaynaklarını kullanarak ısı ve güç üretmek için mükemmel bir seçimdir (Turkan ve Etemoglu, 2020).

ORC sistemlerini tasarım, optimizasyon, çalışma durumu vb. gibi farklı açılardan inceleyen, teknolojinin mevcut durumunu belirlemek ve gelecekteki araştırmalara rehberlik etmek için çok sayıda derleme makalesi yayınlanmıştır (Imran vd., 2018; Garcia vd., 2018). Yamamoto vd., (2001) çalışma akışkanları olarak HCFC-123 ve su kullanarak kapalı tip organik Rankine çevrimlerinin performansını ve özelliklerini inceledi. $\mathrm{Bu}$ çalışmadan, organik Rankine çevriminin düşük dereceli 1S1 kaynaklarıyla etkin bir şekilde uygulanabileceği ve HCFC-123'ün organik Rankine çevrimi performansını önemli ölçüde arttırdığı görülebilir.

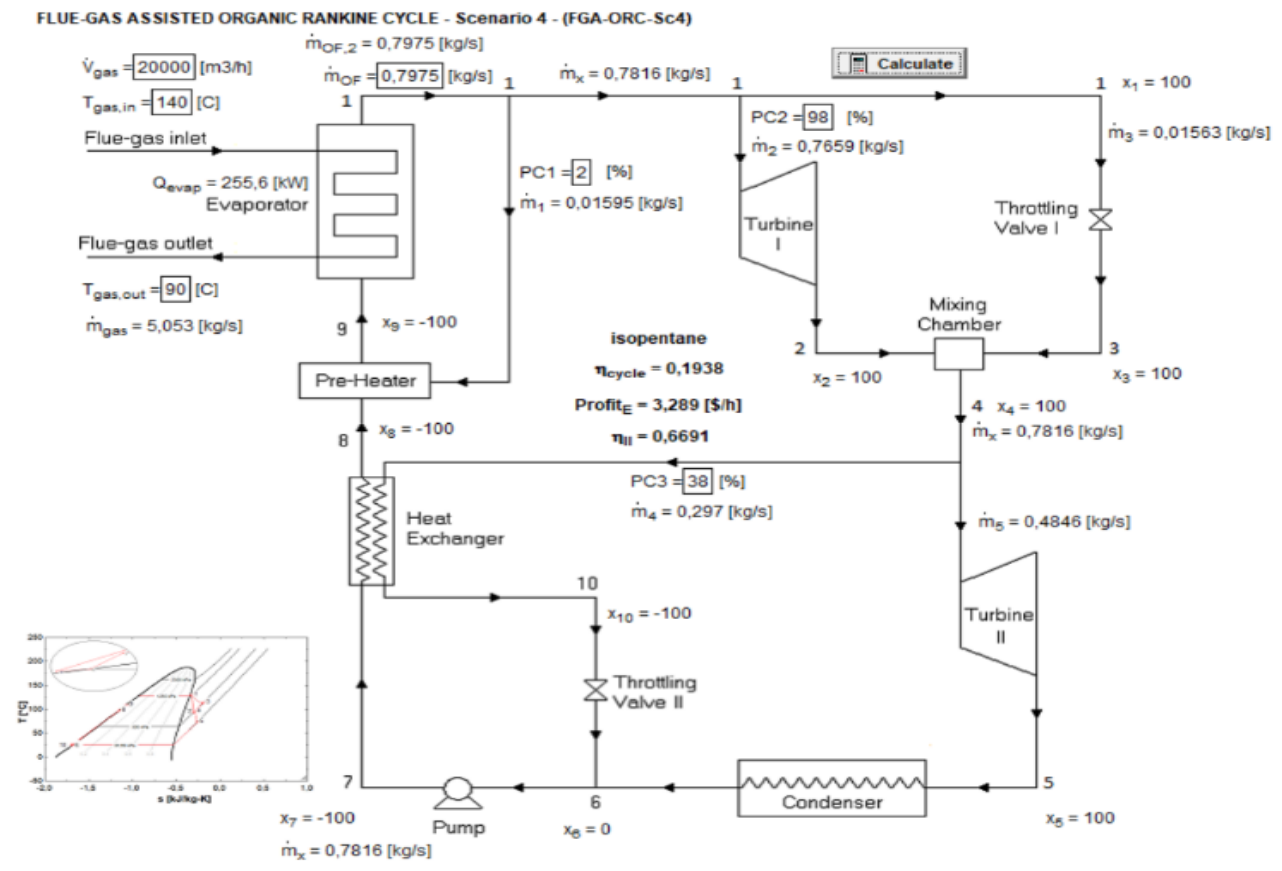

Şekil 1. ORC şeması
Etemoğlu (2008), çalışma koşullarının ve çalışma sıvısının sistem performansını büyük ölçüde değiştirebileceğini kanıtladı. Kermani vd., (2018) çalışma koşullarını ve çalışma akışkanını değiştirerek optimum termal mimariyi elde etmek için bir optimizasyon tekniği sunmuştur. Akbay ve Yılmaz (2021) tarafindan 1sı kaynağı olarak jeotermal enerji kullanılarak farklı akışkanların ORC ve buhar türbinleri üzerindeki etkilerini araştırmak için bir termal analiz yapılmıştır.

Termal işlemlerde muazzam miktarda 1 sı israf edilir. Forman vd., (2016) küresel birincil enerji tüketiminin \%72'sinin termal işlemler sırasında kaybolduğunu ve dikkate alınan atık 1sı akışlarının \%63'ünün $100^{\circ} \mathrm{C}^{\prime}$ nin altında bir sıcaklığa sahip olduğunu tahmin etmektedir.

$\mathrm{Bu}$ çalışmada öncelikle, termal enerjiyi elektrik ve/veya mekanik enerjiye çeviren bir sistemde en iyi çevrim koşullarını bulmak için bir optimizasyon araştırması yapılmıştır. Termodinamiğin birinci ve ikinci yasasını temel alan uygun bir matematiksel model ile ORC'lerin enerji ve ekserji yıkımının hesaplanması için gerekli yöntemler verilmiştir.

\section{Materyal ve Metot}

Çalışmada kullanılan ORC modeli Şekil 1'de verilmiştir. Çalışmada verilen matematiksel ifadeler için EES (Engineering Equation Solver) programı kullanılmıştır. Taguchi analizi için ise Minitab programı kullanılmıştır.

ORC'nin birinci ve ikinci yasa analizleri için aşağıdaki birkaç varsayım kabul edilmiştir.

1. Tüm süreçler, ihmal edilebilir potansiyel ve kinetik enerji etkileri olan ve kimyasal veya nükleer reaksiyon içermeyen kararlı hal ve kararlı akıştır.

2. Sisteme 1Sı geçişi ve sistemden iş geçişi yönleri pozitiftir.

3. Türbin çalışmasının adyabatik verimliliği \%80'dir. 
4. Sirkülasyon pompalarının adyabatik verimleri $\% 85$ 'tir.

5. Basınç düşüşleri göz ardı edilmiştir.

6. Kondenserin çıkış sıcaklığı $25^{\circ} \mathrm{C}$ dir.

7. Ölü hal koşulu $\mathrm{T}_{\mathrm{o}}=20^{\circ} \mathrm{C}$ ve $\mathrm{P}_{\mathrm{o}}=100 \mathrm{kPa}$ olarak alınmıştır.

\subsection{Teorik Analiz}

Ram çerçeveleri, tekstil işlemlerinde yüksek oranda kullanılan sürekli kurutuculardır. Bahsedilen tekstil prosesi sonunda yüksek hacimli baca gazı çevreye atılır. Bu nedenle geri kazanıma uygun düşük sıcaklıktaki baca gazı yeni bir enerji kaynağı adayı olarak değerlendirilmektedir.

Belirli bir durumda bir sistemde bulunan enerjinin iş potansiyeli, sistemden elde edilebilecek maksimum faydalı iştir. $\mathrm{Bu}$ durum ekserji terimi ile ifade edilir. Ekserji, sistem boyunca akan çok çeşitli akışların (kütle, 1sı, iş vb.) yararlı enerjisini veya iş yapma veya alma yeteneğini - iş içeriğini - nicel olarak temsil eder (Cengel ve Boles, 1989). Bu nedenle ekserji analizi, termal sistemlerin tasarımı, analizi ve sınıflandırılması için güçlü bir araçtır. Kinetik ve potansiyel enerji değişimlerini göz ardı ederek, herhangi bir durumda sıvının özgül akış ekserjisi, e, eşitlik 1'den hesaplanabilir.

$e=h-h_{o}-T_{o}\left(s-s_{o}\right)$

Burada $\mathrm{h}$ entalpidir $(\mathrm{kJ} / \mathrm{kg}), \mathrm{s}$ entropidir $(\mathrm{kJ} / \mathrm{kgK}), \mathrm{T}$ sıcaklıktır (K). Özgül ekserji, e, akışkanın kütle akış hızı m ile çarpıldığında ekserji hızı E 'yi verir.

$\dot{E}=\dot{m} e$

Entropi dengesinin oran biçimi şu şekilde ifade edilebilir;

$$
\underbrace{\dot{S}_{\text {in }}-\dot{S}_{\text {out }}}_{\text {Net entropy transfer rate }}=\underbrace{\dot{S}_{\text {gen }}}_{\text {Entropy generation rate }}
$$

ve entropi üretim hızı, $S_{\text {gen, }}$ aşağıdaki denklemden hesaplanabilir;

$\dot{S}_{\text {gen }}=\sum \dot{m}_{\text {out }} S_{\text {out }}-\sum \dot{m}_{\text {in }} s_{\text {in }}-\sum \frac{\dot{Q}}{T}$

Burada Q 1S1 transfer hızıdır. Ekserji yıkım hızı (veya tersinmezlik oranı), I, kararlı hal açık sistem için genel ekserji oranı dengesine dayalı olarak elde edilebilir.

$\dot{I}=T_{0} \dot{S}_{g e n}$

Burada $\mathrm{T}_{0}$ ölü hal sıcaklığıdır. Sistemin toplam ekserji yıkımı

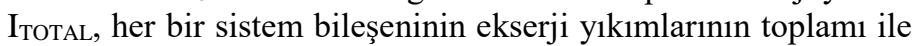
sistemin i. cihazının performans oranı olan $\mathrm{PR}_{\mathrm{i}}$ aşağıdaki denklem ile ifade edilebilir;
$P R_{i}=\frac{\dot{I}_{i}}{\dot{I}_{\text {TOTAL }}}$

İkinci yasa verimliliği, nII, bir cihazın performansının, aynı son durumlar için tersinir koşullar altında performansa oranı olarak ifade edilir (Bejan, 2002; Cengel ve Boles, 1989).

$\eta_{\mathrm{II}}=\frac{\eta}{\eta_{\mathrm{rev}}}$

\subsubsection{Taguchi Analiz Denklemleri}

Maksimum, minimum ve nominal performans değerleri için eşitlik (8), (9) ve (10) kullanılmaktadır (Taguchi, 1990).

$\mathrm{S} / \mathrm{N}_{\max }=-10 \log \left(\frac{1}{\mathrm{n}} \sum_{\mathrm{i}=1}^{\mathrm{n}} \frac{1}{\mathrm{y}_{\mathrm{i}}^{2}}\right)$

$\mathrm{S} / \mathrm{N}_{\min }=-10 \log \left(\frac{1}{\mathrm{n}} \sum_{\mathrm{i}=1}^{\mathrm{n}} \mathrm{y}_{\mathrm{i}}^{2}\right)$

$\mathrm{S} / \mathrm{N}_{\text {nom }}=10 \log \left(\frac{\overline{\mathrm{y}}^{2}}{\mathrm{~s}^{2}}\right)$

$\bar{y}=\frac{1}{n} \sum_{i=1}^{n} y_{i} \quad s^{2}=\frac{1}{n-1} \sum_{i=1}^{n}\left(y_{i}-\bar{y}\right)^{2}$

Burada $\mathrm{n}$ bir denemedeki test sayısı, $\mathrm{y}_{\mathrm{i}}$ performans karakteristikleri için simülasyondan elde edilen verinin i. değeri, $\bar{y}$ gözlem değerlerinin ortalaması ve $s^{2}$ gözlem değerlerinin varyansıdır. Simülasyon ile elde edilen veriler Taguchi yöntemi ile yapılan analiz sonucunda aynı zamanda tahmin edilebilir.

\section{Araştırma Sonuçları ve Tartışma}

Bu çalışmada öncelikle ORC sürecine etki eden parametreleri (Türbin giriş basıncı $\mathrm{P}_{1}$, Çevrim ara basıncı $\mathrm{P}_{2}$ ve Türbinden ara basınçtaki isı eşanjörüne aktarılan akışkan oranı PC3) optimize etmek için Taguchi metodu kullanıldı. Analizlerde türbin giriş basınc $1000 \mathrm{kPa}, 1200 \mathrm{kPa}$ ve $1311 \mathrm{kPa}$, çevrim ara basıncı $300 \mathrm{kPa}, 350 \mathrm{kPa}$ ve $400 \mathrm{kPa}$ ve türbinden ara basınçtaki $1 \mathrm{~s} 1$ eşanjörüne aktarılan akışkan oranı 30,35 ve 38 alınmıştır (Çizelge 1). ORC parametrelerinin seviyelerini temsil eden örneklerin sayısal değerleri ve Taguchi L9 ortogonal dizi kullanılarak seçilen simülasyon sırası Çizelge 2'da ifade edilmiştir. Burada verilen değerler Minitab programına girilmiştir. 9 farklı değer ile Taguchi analizi gerçekleştirilmiştir. Analizler termodinamiğin birinci kanun verimi ve ikinci kanun verimi dikkate alınarak yapıldı. Tüm bu çıktı değerleri maksimum amaç fonksiyonu olarak tanımlandı. 
Çizelge 1. Çalışmada kullanılan ORC parametreleri ve seviyeleri

\begin{tabular}{|c|c|c|c|c|}
\hline Parametre & $\begin{array}{c}\text { Serbestlik } \\
\text { derecesi }\end{array}$ & $\begin{array}{c}\text { Level } \\
1\end{array}$ & $\begin{array}{c}\text { Level } \\
2\end{array}$ & $\begin{array}{c}\text { Level } \\
3\end{array}$ \\
\hline Türbin & 2 & 1000 & 1200 & 1311 \\
\hline \multicolumn{5}{|l|}{ Basınc1 (kPa) } \\
\hline $\begin{array}{l}\text { Çevrim ara } \\
\text { basıncı }(\mathrm{kPa})\end{array}$ & 2 & 300 & 350 & 400 \\
\hline Türbinden Ara & & & & \\
\hline Basınçtaki $\quad$ Isı & 2 & 30 & 35 & 38 \\
\hline \multicolumn{5}{|l|}{ Eşanjörüne } \\
\hline \multicolumn{5}{|l|}{ Aktarılan } \\
\hline \multicolumn{5}{|l|}{ Akışkan Oranı } \\
\hline \multicolumn{5}{|l|}{ Toplam } \\
\hline $\mathrm{SD}$ & 6 & & & \\
\hline
\end{tabular}

Çizelge 2. Taguchi ortogonal L9 dizisi kullanılarak seçilen parametreler ve seviyeleri

\begin{tabular}{|c|c|c|c|c|}
\hline $\begin{array}{l}\text { Ortogonal } \\
\text { dizi }\end{array}$ & $\begin{array}{c}\text { Analiz } \\
\text { no }\end{array}$ & $\begin{array}{l}\text { Türbin } \\
\text { Giriş } \\
\text { Basınc1 } \\
(\mathrm{kPa}) \\
\mathrm{P}_{1}\end{array}$ & $\begin{array}{c}\text { Çevrim } \\
\text { ara } \\
\text { basıncı } \\
(\mathrm{kPa}) \\
\mathrm{P}_{2}\end{array}$ & $\begin{array}{c}\text { Türbinden Ara } \\
\text { Basınçtaki Isı } \\
\text { Eşanjörüne } \\
\text { Aktarılan } \\
\text { Akışkan Oranı } \\
\text { PC3 }\end{array}$ \\
\hline 111 & 1 & 1000 & 300 & 30 \\
\hline 122 & 2 & 1000 & 350 & 35 \\
\hline 133 & 3 & 1000 & 400 & 38 \\
\hline 212 & 4 & 1250 & 300 & 35 \\
\hline 223 & 5 & 1250 & 350 & 38 \\
\hline 231 & 6 & 1250 & 400 & 30 \\
\hline 313 & 7 & 1311 & 300 & 38 \\
\hline 321 & 8 & 1311 & 350 & 30 \\
\hline 332 & 9 & 1311 & 400 & 35 \\
\hline
\end{tabular}

\subsection{Birinci Kanun Verimi için Optimizasyon Çalışması}

ORC çevrimi işleminde 9 farklı senaryoya ile hesaplanan termodinamiğin 1. kanunu verileri Minitab 18 programında Taguchi analiz modülüne girilmiştir. Sonrasında Taguchi analiz metodu kullanılarak ANOVA sonuçları elde edilmiştir. Çizelge 3 elde edilen birinci kanun ve hesaplanan $\mathrm{S} / \mathrm{N}$ oran değerlerini göstermektedir. En fazla birinci kanun değeri en büyük ortalama $\mathrm{S} / \mathrm{N}$ oranında elde edilmektedir. Şekil $2 \mathrm{a}$ 'da hesaplanan ortalama $\mathrm{S} / \mathrm{N}$ oranlarının analizine göre optimum koşul olan en fazla birinci kanun, en büyük ortalama $\mathrm{S} / \mathrm{N}$ oranlarının elde edildiği $1311 \mathrm{kPa}$ türbin giriş basınc1, $300 \mathrm{kPa}$ çevrim ara basıncı ve 38 türbinden ara basınçtaki isı eşanjörüne aktarılan akışkan oranı olarak elde edilmiştir. ANOVA metodu bize tüm etmenlerin önemini ve birbiri ile olan etkileşimlerini önceden incelememize imkan sağlar. Bu çalışmada parametrelerin birer birer katkısını elde etmek için ortalama $\mathrm{S} / \mathrm{N}$ değerlerini kullanarak ANOVA yöntemi incelendi. Çizelge 4'de verilen parametrelerin çevrimin birinci kanunu üzerindeki etki oranları ile ANOVA sonuçları sunulmuştur. $\mathrm{Bu}$ yüzde oranları Şekil $2 \mathrm{~b}$ 'de ifade edilmiştir. Rankine çevriminde birinci kanun üzerinde türbin giriş basıncının etkisinin yaklaşık \% 70,23 , çevrim ara basıncının etkisinin $\% 11,35$ ve türbinden ara basınçtaki isı eşanjörüne aktarılan akışkan oranının etkisinin ise $\% 18,27$ olduğu elde edilmiştir. Bu sonuca göre termodinamiğin birinci kanunu üzerine etki eden parametrelerin önem sırası türbin giriş basınc1> türbinden ara basınçtaki isı eşanjörüne aktarılan akı̧̧kan oranı $>$ çevrim ara basınc1 olarak elde edilmiștir. Rankine çevriminde termodinamiğin birinci kanunu üzerinde en önemli parametre türbin giriş basıncıdır. Çizelge 5 'de $\mathrm{S} / \mathrm{N}$ oranı cevap sonuç tablosuna göre de en önemli (1 numaral1) parametrenin türbin giriş basıncı olduğu görülmektedir.

Çizelge 3. ORC çevriminin birinci kanun değerleri ve hesaplanan S/N oranı

\begin{tabular}{lcc}
\hline Ortogonal dizi & Termodinamiğin 1.kanunu & S/N oranı \\
\hline 111 & 0,166 & $-15,5701$ \\
122 & 0,1681 & $-15,4886$ \\
133 & 0,1678 & $-15,5042$ \\
212 & 0,1863 & $-14,5911$ \\
223 & 0,1867 & $-14,5725$ \\
231 & 0,1739 & $-15,1940$ \\
313 & 0,1938 & $-14,2529$ \\
321 & 0,1792 & $-14,9332$ \\
332 & 0,1822 & $-14,7890$ \\
\hline
\end{tabular}

Çizelge 4. S/N oranı için varyans analizi

\begin{tabular}{lrrrrr}
\hline Kaynak & DF & Seq SS & AdjSS & Adj MS & F \\
P1 & 2 & 1,3006 & 1,3006 & 0,65031 & 648,7 \\
P2 & 2 & 0,1923 & 0,1923 & 0,09618 & 95,95 \\
PC3 & 2 & 0,3164 & 0,3164 & 0,15822 & 157,8 \\
Hata & 2 & 0,0020 & 0,0020 & 0,00100 & \\
Total & 8 & 1,8114 & & & \\
\hline
\end{tabular}

Çizelge 5. S/N oranı için cevap sonuç tablosu

\begin{tabular}{lrrr}
\hline Level & P1 & P2 & PC3 \\
1 & $-15,52$ & $-14,80$ & $-15,23$ \\
2 & $-14,79$ & $-15,00$ & $-14,96$ \\
3 & $-14,66$ & $-15,16$ & $-14,78$ \\
Delta & 0,86 & 0,36 & 0,46 \\
Rank & 1 & 3 & 2 \\
\hline
\end{tabular}




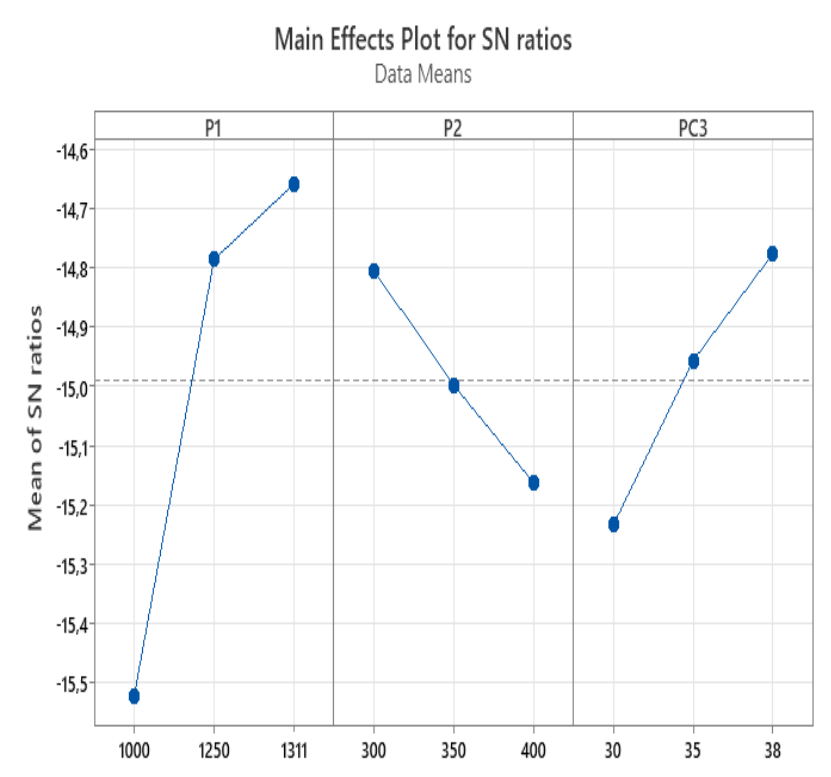

Signal-to-noise: Larger is better

(a)

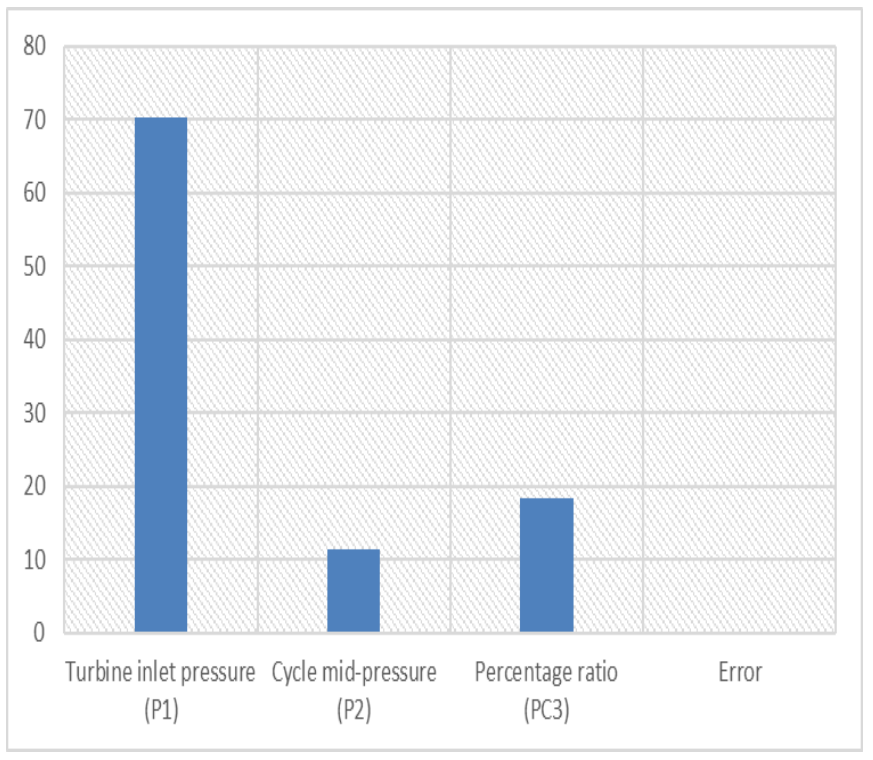

(b)

Şekil 2. a) Farklı ORC parametreleri için birinci kanunun $S / N$ oranı b) Parametrelerin birinci kanun üzerindeki etki yüzdeleri

\section{2. İkinci Kanun Verimi için Optimizasyon Çalışması}

ORC çevrimi işleminde 9 farklı senaryoya ile hesaplanan termodinamiğin 2. kanunu verileri Minitab 18 programında Taguchi analiz modülüne girilmiştir. Sonrasında Taguchi analiz metodu kullanılarak ANOVA sonuçları elde edilmiştir. Çizelge 6 elde edilen ikinci kanun ve hesaplanan $\mathrm{S} / \mathrm{N}$ oran değerlerini göstermektedir. En fazla ikinci kanun değeri en büyük ortalama $\mathrm{S} / \mathrm{N}$ oranında elde edilmektedir. Şekil 3a'da hesaplanan ortalama $\mathrm{S} / \mathrm{N}$ oranlarının analizine göre optimum koşul olan en fazla ikinci kanun, en büyük ortalama $\mathrm{S} / \mathrm{N}$ oranlarının elde edildiği $1311 \mathrm{kPa}$ türbin giriş basıncı, $300 \mathrm{kPa}$ çevrim ara basıncı ve 38 türbinden ara basınçtaki isı eşanjörüne aktarılan akışkan oranı olarak elde edilmiştir. Çizelge 7'de verilen parametrelerin çevrimin ikinci kanunu üzerindeki etki oranları ile ANOVA sonuçları sunulmuştur. Bu yüzde oranları Şekil 3b'de ifade edilmiştir.

Rankine çevriminde ikinci kanun üzerinde türbin giriş basıncının etkisinin yaklaşık $\% 72,38$, çevrim ara basıncının etkisinin $\% 9,78$ ve türbinden ara basınçtaki isı eşanjörüne aktarılan akışkan oranının etkisinin ise $\% 17,74$ olduğu elde edilmiştir. Bu sonuca göre termodinamiğin ikinci kanunu üzerine etki eden parametrelerin önem sırası türbin giriş basınc1> türbinden ara basınçtaki isı eşanjörüne aktarılan akışkan oranı > çevrim ara basıncı olarak elde edilmiştir. Rankine çevriminde termodinamiğin ikinci kanunu üzerinde de en önemli parametre türbin giriş basıncıdır. Çizelge 8 'de $\mathrm{S} / \mathrm{N}$ oranı cevap sonuç tablosuna göre de en önemli (1 numaralı) parametrenin türbin giriş basıncı olduğu görülmektedir.

Çizelge 6. ORC çevriminin ikinci kanun değerleri ve hesaplanan S/N oranı

\begin{tabular}{ccc}
\hline Ortogonal dizi & Termodinamiğin 2.kanunu & $\mathrm{S} / \mathrm{N}$ oranı \\
\hline 111 & 0,5731 & $-4,83590$ \\
122 & 0,5806 & $-4,72296$ \\
133 & 0,5795 & $-4,74043$ \\
212 & 0,6434 & $-3,83038$ \\
223 & 0,6445 & $-3,81554$ \\
231 & 0,6006 & $-4,42829$ \\
313 & 0,6691 & $-3,49148$ \\
321 & 0,6189 & $-4,16759$ \\
332 & 0,6291 & $-4,02561$ \\
\hline
\end{tabular}

Çizelge 7. S/N oranı için varyans analizi

\begin{tabular}{lrrrrr}
\hline Kaynak & DF & Seq SS & Adj SS & Adj MS & F \\
P1 & 2 & 1,3265 & 1,3265 & 0,66327 & 847,0 \\
P2 & 2 & 0,1792 & 0,1792 & 0,08964 & 114,4 \\
PC3 & 2 & 0,3251 & 0,3251 & 0,16256 & 207,6 \\
Hata & 2 & 0,00157 & 0,00157 & 0,000783 & \\
Total & 8 & 1,83252 & & & \\
\hline
\end{tabular}

Çizelge 8. S/N oranı için cevap sonuç tablosu

\begin{tabular}{lrrr}
\hline Level & P1 & P2 & PC3 \\
1 & $-4,766$ & $-4,053$ & $-4,477$ \\
2 & $-4,025$ & $-4,235$ & $-4,193$ \\
3 & $-3,895$ & $-4,398$ & $-4,016$ \\
Delta & 0,872 & 0,346 & 0,461 \\
Rank & 1 & 3 & 2 \\
\hline
\end{tabular}




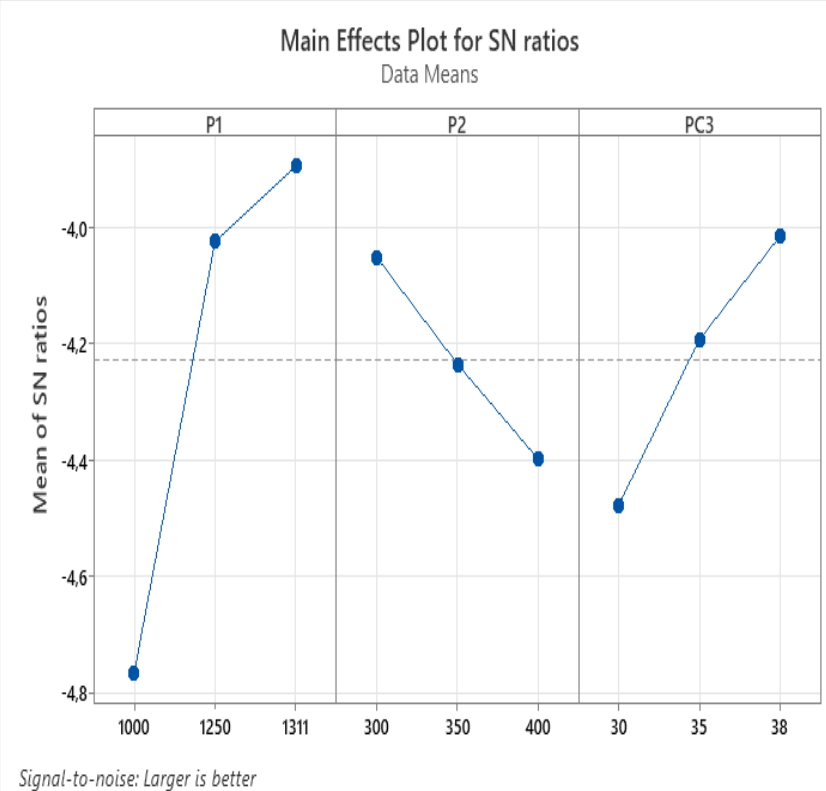

(a)

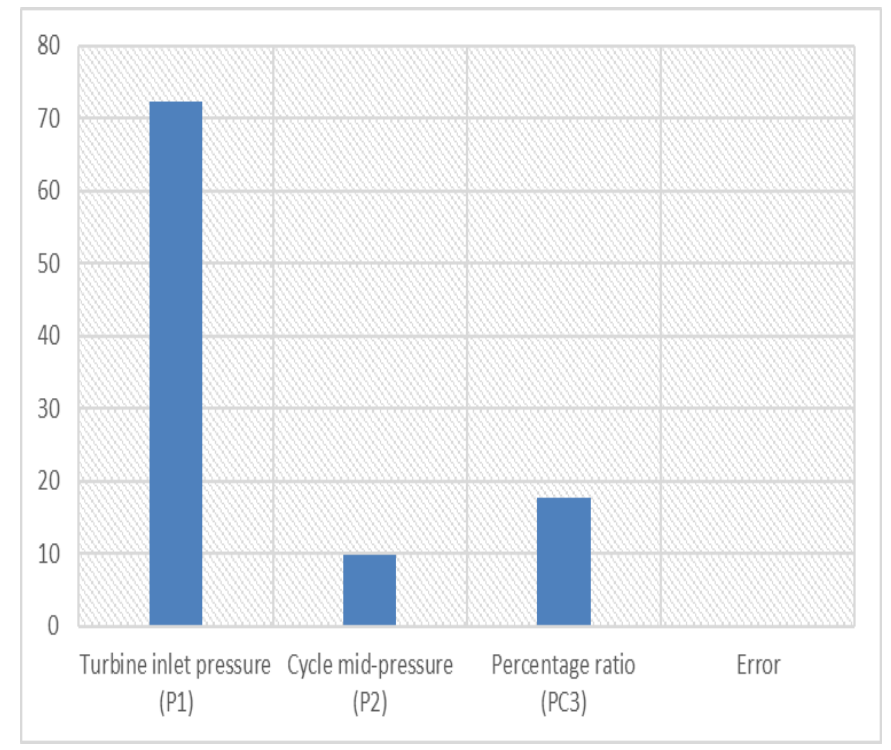

(b)

Şekil 3. a) Farklı ORC parametreleri için ikinci kanunun $S / N$ oranı b) Parametrelerin ikinci kanun üzerindeki etki yüzdeleri

\section{Sonuç}

Enerji üretimindeki yüksek maliyetler, daha sıkı çevre mevzuatı ve küresel sürdürülebilir kalkınma hedefleri nedeniyle atık ısı geri kazanım süreçlerinin önemi artmaktadır. ORC'ler, bu açıdan hedeflere ulaşmak için umut verici bir teknolojidir. $\mathrm{Bu}$ çalışmada, baca gazı destekli atık 1sı geri kazanımı için yüksek verim ve düşük çevresel etkiler sağlamak için organik akışkan olarak izopentan kullanılarak termal mimari incelenmiştir. Sunulan termodinamik ve çevresel analize dayanarak, aşağıdaki sonuçlar çıkarılmıştır:

$\mathrm{Bu}$ çalışmada ORC sürecine etki eden parametrelerin (Türbin giriş basıncı P1, çevrim ara basıncı $\mathrm{P} 2$ ve türbinden ara basınçtaki 1s1 eşanjörüne aktarılan akışkan oranı PC3) etkisini incelemek için birinci ve ikinci kanun verim değerleri hesaplanmıştır. ORC çevrimi üzerinde her iki verim değeri için en etkili parametrenin türbin giriş basıncı olduğu görülmüştür.
Birinci ve ikinci kanun değerleri türbin giriş basınç değerinin ve 1sı eşanjörüne aktarılan akışkan oranının artışı ile arttığı tespit edilmiştir.

Sunulan optimizasyon stratejisi, bilinen termodinamik kısıtlamalar için farklı termal mimarilerin optimal tasarımını belirlemek için faydalı bir yöntemdir. Bu çalışmada elde edilen sonuçlar, temel performans göstergelerine dayalı olarak ORC'ler için optimum kontrol ve operasyon stratejisinin daha iyi anlaşılmasını sağlayacaktır.

\section{Kaynakça}

Akbay, O., Yılmaz, F. (2021). Thermodynamic Analyzes and Performance Comparison of Flash Binary Geothermal Power Generation Plant, El Cezeri, 8(1), pp.445-461.

Alirahmi, S.M., Assareh, E., Chitsaz, A., Holagh, S.G., Jalilinasrabady, S. (2021). Electrolyzer-fuel cell combination for grid peak load management in a geothermal power plant: Power to hydrogen and hydrogen to power conversion, Int J Hydrogen Energy, 46(50), pp.25650-65.

Bejan, A. (2002). Fundamentals of exergy analysis, entropy generation minimization, and the generation of flow architecture, Int. J. Energy Research, 26, pp.545-565.

Cengel, Y.A., Boles, B.A. (1989). Thermodynamics : An engineering approach. Singapore: McGraw Hill Book Co.

Etemoglu, A.B. (2008). Thermodynamic evaluation of geothermal power generation systems in Turkey, Energy Sources, Part A, 30, pp. 905-916.

Forman, C., Muritala, I.K., Pardemann, R., Meyer, B. (2016). Estimating the global waste heat potential, Renewable and Sustainable Energy Reviews, 57, pp.1568-1579.

Garcia, S.I., Garcia, R.F., Carril, J.C., Garcia, D.I. (2018). A review of thermodynamic cycles used in low temperature recovery systems over the last two years, Renewable and Sustainable Energy Reviews, 81, pp.760-767.

Imran, M., Haglind, F., Asim, M., Alvi, J.Z. (2018). Recent research trends in organic Rankine cycle technology - A bibliometric approach, Renewable and Sustainable Energy Reviews, 81, pp.552-562.

Kermani, M., Wallerand, A.S., Kantor, I.D., Maréchal, F. (2018). Generic Superstructure Synthesis of Organic Rankine Cycles for Waste Heat Recovery in Industrial Processes, Applied Energy, 212, pp.1203-1225.

Pulat, E., Etemoglu, A.B., Can, M. (2009). Waste heat recovery potential in Turkish textile industry: case study for city of Bursa, Renewable and Sustainable Energy Reviews, 13(3), pp.663-672.

Soltani, M., Nabat, M.H., Razmi, A.R., Dusseault, M.B., Nathwani, J. (2020). A comparative study between ORC and Kalina based waste heat recovery cycles applied to a green compressed air energy storage (CAES) system, Energy Convers Manag., 222, 113203.

Taguchi, G. (1990). Introduction to quality engineering. Asian Productivity Organization, Tokyo.

Turkan, B., Etemoglu, A.B. (2020). Performance Evaluation For Thermal Architectures of Flue-Gas Assisted Organic Rankin Cycle Systems, J. of Thermal Science and Technology, 40(1), pp.65-76.

Yamamoto, T., Furuhata, T., Arai, N., Mori, K. (2001). Design and testing of the organic Rankine cycle, Energy, 26, pp.239-251. 